\title{
Effects of Voluntary Running Exercise on Skeletal Muscle Properties in Nonobese Rats with Type 2 Diabetes
}

\author{
Isuzu NAKAMOTO ${ }^{1}$, Akihiko ISHIHARA ${ }^{1}$ \\ ${ }^{1}$ Laboratory of Cell Biology and Life Science, Graduate School of Human and Environmental \\ Studies, Kyoto University, Kyoto, Japan
}

Received April 4, 2019

Accepted September 25, 2019

Epub Ahead of Print December 19, 2019

\section{Summary}

The skeletal muscles of animals and humans with type 2 diabetes have decreased oxidative capacity. Aerobic exercise can improve muscle oxidative capacity, but no data are available on the amount of exercise required. We investigated the effects of voluntary running exercise and running distance on the skeletal muscle properties of nonobese rats with type 2 diabetes. Six-week-old male diabetic Goto-Kakizaki rats were divided into nonexercised (GK) and exercised (GK-Ex) groups. The rats in the GK-Ex group were permitted voluntary running exercise on wheels for 6 weeks. Age-matched male Wistar rats (WR) were used as nondiabetic controls. Fasting blood glucose and $\mathrm{HbA1c}$ levels were higher in the GK and GK-Ex groups than in the WR group and lower in the GK-Ex group than in the GK group. Succinate dehydrogenase (SDH) activity and peroxisome proliferator-activated receptor $y$ coactivator-1a (Pgc-1a) mRNA levels in the soleus and plantaris muscles were higher in the WR and GK-Ex groups than in the GK group. HbA1c and total cholesterol levels were negatively correlated with running distance and SDH activity and Pgc-1a mRNA levels in the soleus muscle were positively correlated with running distance. The onset and progression of diabetes in nonobese diabetic rats were effectively inhibited by running longer distances.

\section{Key words}

Goto-Kakizaki rat • Oxidative capacity • Pgc-1a mRNA • Skeletal muscle $\bullet$ Type 2 diabetes $\bullet$ Voluntary running exercise

\section{Corresponding author}

A. Ishihara, Laboratory of Cell Biology and Life Science, Graduate School of Human and Environmental Studies, Kyoto University, Kyoto 606-8501, Japan. Fax: +81-75-753-6771. E-mail: ishihara.akihiko.8s@kyoto-u.ac.jp

\section{Introduction}

The metabolic properties of skeletal muscle, an organ responsible for a major portion of glucose disposal, play an important role in the onset and progression of type 2 diabetes (Phielix and Mensink 2008). The skeletal muscles of experimental animals with type 2 diabetes have decreased oxidative capacity; that is, reduced succinate dehydrogenase $(\mathrm{SDH})$ activity and peroxisome proliferator-activated receptor $\gamma$ coactivator$1 \alpha(P g c-1 \alpha)$ mRNA levels (Nagatomo et al. 2009, Nagatomo et al. 2011a).

Aerobic exercise has been shown to effectively prevent and/or improve insulin resistance and impaired glucose metabolism (Ishihara et al. 2012, Jenkins and Jenks 2017). Aerobic exercise restored the decreased oxidative capacity of skeletal muscles and improved hyperglycemia in obese rats with type 2 diabetes (Yasuda et al. 2006).

PGC- $1 \alpha$ is a major regulator of oxidative metabolism in skeletal muscles (Puigserver 2005, Wende et al. 2005). High Pgc-1a mRNA levels induced increases in mitochondrial content and the percentage of high-oxidative fibers in skeletal muscles (Lin et al. 2002, Schuler et al. 2006, Wu et al. 2002). Diabetic rats showed growth-related decreases in the percentage of highoxidative fibers and SDH activity in skeletal muscles (Yasuda et al. 2007). Therefore, an exercise-induced increase in $P g c-1 \alpha$ mRNA levels in skeletal muscles is expected to lead to a fiber type shift and improve muscle SDH activity. Previous studies (Fu et al. 2019, Kim et al. 2011, Macia et al. 2018, Morifuji et al. 2012, Qi et al. 2011) examined the effects of running exercise on 
diabetes; however, these studies used forced running training on a treadmill, and the amount of exercise was constant for all exercised rats. Furthermore, treadmill exercise is stressful because the rats are forcibly run at a constant speed. In this study, we investigated the effects of voluntary running exercise and running distance on the properties of skeletal muscle in diabetic rats, because it is uncertain whether voluntary running distance is related to the improvement of hyperglycemia and decreased muscle oxidative capacity in diabetic rats. We investigated the effects of voluntary running exercise and running distance on the properties of the slow soleus and fast plantaris muscles in diabetic Goto-Kakizaki (GK) rats.

\section{Methods}

\section{Ethical approval}

All experimental and animal care procedures were conducted in accordance with the Guide for the Care and Use of Laboratory Animals issued by the Institutional Animal Experiment Committee of Kyoto University (Kyoto, Japan) as well as national guidelines and relevant national laws on the protection of animals.

\section{Experimental animals}

The nonobese experimental animals with type 2 diabetes used in this study were GK rats, which have low oxidative capacity in skeletal muscles compared to nondiabetic rats (Nagatomo et al. 2009, Nagatomo et al. 2011a). These rats were established by repeated inbreeding of normal Wistar rats with glucose tolerance at the upper limit of the normal range (Goto et al. 1975, 1976). Six-week-old male GK rats were assigned to either the non-exercised (GK, n=5) or exercised (GK-Ex, n=10) group based on their body weights and fasting blood glucose levels, such that the mean values of these parameters in the two groups were similar. Age-matched male Wistar rats were used as nondiabetic controls (WR, $\mathrm{n}=5)$. All rats had free access to a standard diet $(M F$; Oriental East, Tokyo, Japan) and water. The rats were housed under controlled conditions at $22 \pm 2{ }^{\circ} \mathrm{C}$ with a 12-h light/dark cycle (light from 08:00 to 20:00) and $45-55 \%$ relative humidity. The body weight and food intake of each rat were measured once every 2 weeks.

\section{Voluntary running exercise}

Each rat in the GK-Ex group was allowed to run voluntarily on a running wheel (diameter, $31.8 \mathrm{~cm}$; width, $10 \mathrm{~cm}$ ) that was attached to a breeding cage for small animals at its own pace $24 \mathrm{~h}$ a day for 6 weeks (Ishihara et al. 1998). The number of revolutions of each running wheel was recorded daily.

\section{Fasting blood glucose and HbAlc analyses}

Fasting blood glucose was measured once every 2 weeks after fasting for $15 \mathrm{~h}$ using blood samples collected from the tail vein of conscious rats with a blood glucose meter (GT-1650; Arkray, Kyoto, Japan). At 12 weeks of age, HbAlc levels were analyzed using the same blood glucose meter and a DCA Vantage analyzer (Siemens Healthcare Diagnostics, Erlangen, Germany).

\section{Serum biochemical analyses}

After collecting blood samples from the tail vein at 12 weeks of age, the rats were deeply anesthetized, and blood samples were obtained from the abdominal aorta. Total cholesterol, high density lipoprotein (HDL) and low density lipoprotein (LDL) cholesterol, and triglyceride levels were measured using routine laboratory methods. Insulin, high molecular weight adiponectin, and leptin levels were measured using an enzyme-linked immunosorbent assay kit (Shibayagi Corporation, Gunma, Japan).

\section{Muscle histochemical analyses}

After collecting blood samples, the soleus and plantaris muscles were bilaterally dissected, cleaned of excess fat and connective tissue, wet-weighed, and subjected to histochemical, biochemical, and mRNA analyses. The right soleus and plantaris muscles were pinned on a corkboard near their approximate in vivo length and rapidly frozen in isopentane, which was previously cooled using a mixture of dry ice and acetone, and stored at $-80{ }^{\circ} \mathrm{C}$ until analysis. The muscle was mounted onto a specimen chuck with Tissue-Tek OCT compound (Sakura Finetek Japan, Tokyo, Japan). Serial transverse sections (16 $\mu \mathrm{m}$ thick) were cut with a cryostat at $-25{ }^{\circ} \mathrm{C}$, brought to room temperature, air dried for $30 \mathrm{~min}$, and preincubated in acidic ( $\mathrm{pH} 4.5)$ and/or alkaline ( $\mathrm{pH}$ 10.4) conditions for ATPase staining. Soleus muscle fibers were classified as type I (positive response at $\mathrm{pH} 4.5$ and negative response at $\mathrm{pH} 10.4$ ), type IIA (negative response at $\mathrm{pH} 4.5$ and positive response at $\mathrm{pH} 10.4$ ), or type IIC (positive response at $\mathrm{pH} 4.5$ and 10.4) (Nagatomo et al. 2011b, Nagatomo et al. 2012a, Nagatomo et al. 2012b). Plantaris muscle fibers were classified as type I (positive response at $\mathrm{pH} 4.5$ ), type IIA (negative response at $\mathrm{pH} 4.5$ ), or type IIB (intermediate 
response at $\mathrm{pH} 4.5$ ) (Nagatomo et al. 2011a, Nagatomo et al. 2011b).

The fiber type percentage and cross-sectional area (CSA) were determined for approximately 100 adjacent fibers in the central region of the muscle sections. Fiber CSA was measured by tracing the outline of each fiber in the muscle section using a computerassisted image processing system (Neuroimaging System, Kyoto, Japan) (Nagatomo et al. 2011b).

\section{Muscle biochemical analyses}

The left soleus and plantaris muscles were divided into the proximal and distal regions for biochemical and histochemical analyses, respectively. The proximal regions of the left soleus and plantaris muscles were frozen rapidly in liquid nitrogen for the evaluation of SDH activity (Nagatomo et al. 2011b). The muscle was homogenized in five volumes of ice-cold $0.3 \mathrm{M}$ phosphate buffer ( $\mathrm{pH} 7.4$ ) using a glass tissue homogenizer. The final concentrations of the reaction mixture components were as follows: sodium succinate, $17 \mathrm{mM}$; sodium cyanide, $1 \mathrm{mM}$; aluminum chloride, $0.4 \mathrm{mM}$; and calcium chloride, $0.4 \mathrm{mM}$. Reduction of cytochrome $c$ in this reaction mixture was analyzed by measuring the increase in extinction at $550 \mathrm{~nm}$ with a spectrophotometer. SDH activity was calculated from the ferricytochrome $c$ concentration and protein content.

\section{Muscle mRNA analysis}

The distal regions of the left soleus and plantaris muscles were rapidly frozen in liquid nitrogen, and total RNA was extracted from the tissues using the QuickGene RNA Tissue Kit SII (Fujifilm, Tokyo, Japan). Reverse transcription was performed using the High-Capacity cDNA Archive Kit (Applied Biosystems, CA, USA), and the resultant cDNA samples were stored. Pgc-1 $\alpha$ expression levels were quantified by TaqMan Gene Expression Assays (Applied Biosystems, CA, USA) as described previously (Nagatomo et al. 2011b). Each TaqMan probe and primer set was validated by quantitative real-time polymerase chain reaction with a series of cDNA template dilutions to obtain standard curves of the threshold cycle against the relative concentration of $S 18$ (housekeeping gene) as an internal standard. All sample and non-template control reactions were performed in a 7500 Fast Sequence Detection System (Applied Biosystems, CA, USA). Target mRNA levels were normalized to the levels in the WR group.

\section{Statistical analyses}

Values are expressed as mean \pm standard deviation (SD). Analysis of variance followed by Scheffé's post hoc test was used to evaluate differences among the WR, GK, and GK-Ex groups. Correlations were assessed using Pearson's correlation coefficient. Statistical significance was set at $p<0.05$.

\section{Results}

\section{Voluntary running distance}

The voluntary running distances in the GK-Ex group increased every week (Fig. 1). The mean running distance during the 6 weeks of voluntary running exercise was $4.7 \pm 1.2 \mathrm{~km} /$ day.

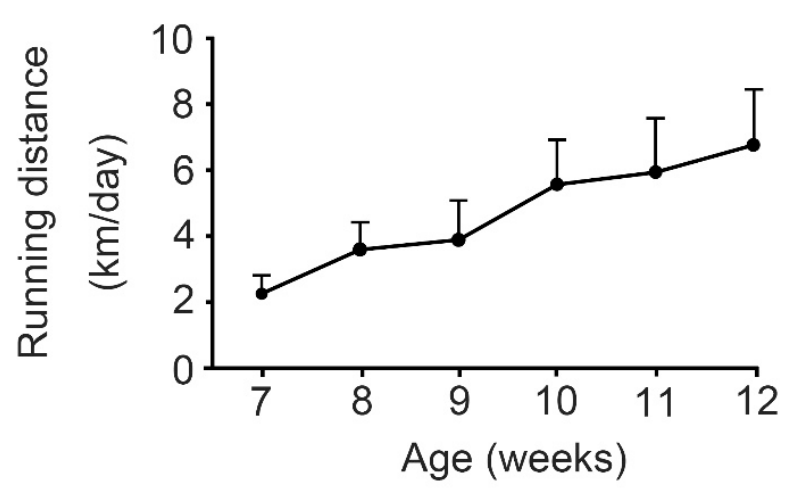

Fig. 1. Voluntary running distance in exercised Goto-Kakizaki rats. Each rat in the GK-Ex group was allowed to voluntarily run in a running wheel that was attached to a breeding cage for small animals at its own pace for $24 \mathrm{~h}$ a day during the 6 weeks of voluntary running exercise. Values are expressed as mean \pm SD $(n=10)$.

\section{Body weight}

The body weights of the WR, GK, and GK-Ex groups increased every week (Fig. 2A). There were no differences in body weight among the age-matched three groups, irrespective of age.

\section{Food intake}

At 6 weeks of age, food intake was lower in the GK-Ex group than in the WR and GK groups $(p<0.05$, Fig. 2B). At 8 weeks of age, food intake was higher in the GK-Ex group than in the WR group $(p<0.05)$. At 10 and 12 weeks of age, food intake was higher in the GK-Ex group than in the WR and GK groups $(p<0.05)$.

Fasting blood glucose levels

At 8,10 , and 12 weeks of age, fasting blood 
glucose levels were higher in the GK group than in the WR group $(p<0.05)$ and lower in the GK-Ex group than in the GK group $(p<0.05$, Fig. $2 \mathrm{C})$.
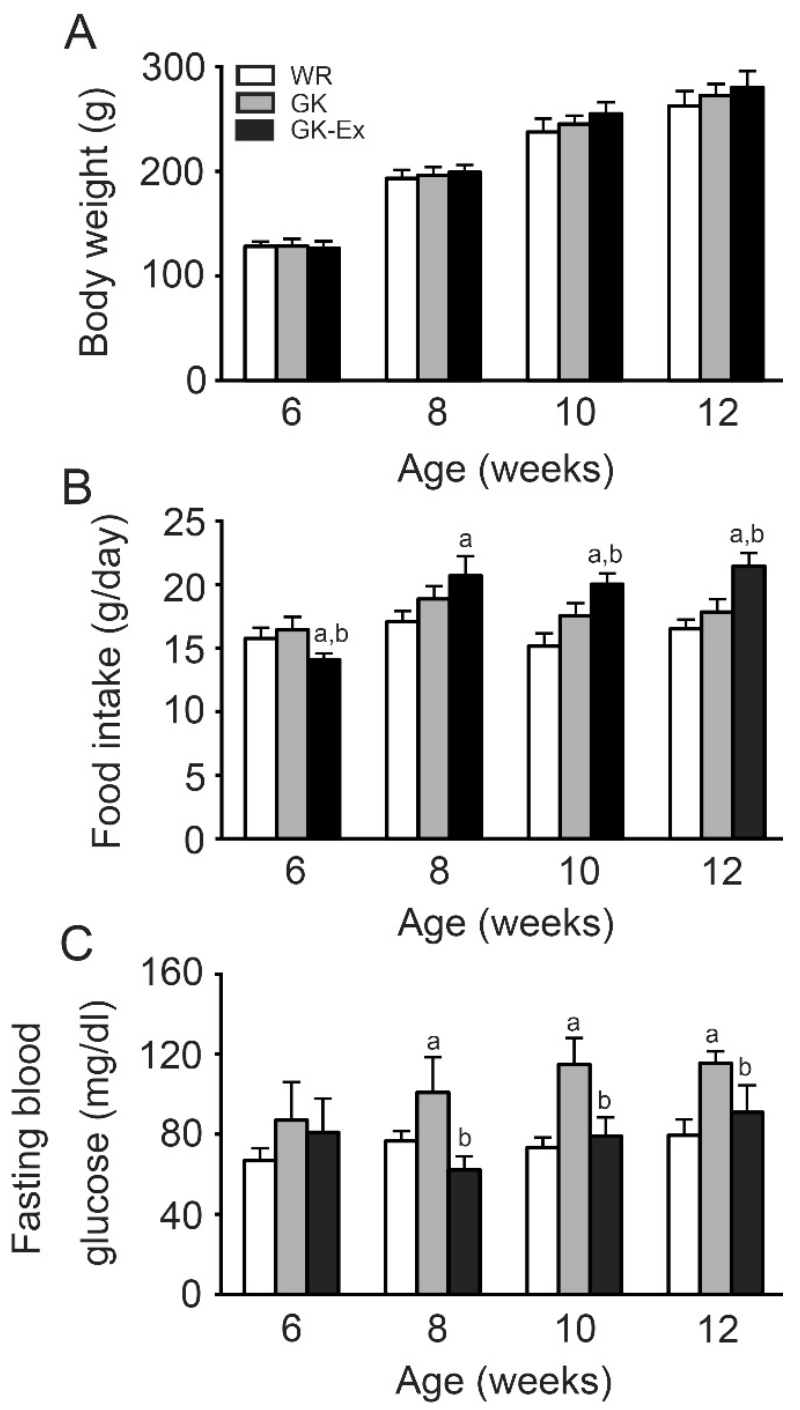

Fig. 2. Body weight (A), food intake (B), and fasting blood glucose (C) in the Wistar (WR), Goto-Kakizaki (GK), and exercised Goto-Kakizaki (GK-Ex) groups. Blood glucose levels were measured after fasting for $15 \mathrm{~h}$ using blood samples collected from the tail vein of conscious rats. Values are expressed as mean $\pm S D$ ( $n=5$ for WR and GK; $n=10$ for GK-Ex). a $p<0.05$ compared with WR; ${ }^{b} p<0.05$ compared with GK.

\section{Serum biochemical parameters}

HbA1c (Fig. 3A) and total cholesterol (Fig. 3B) levels were higher in the GK group than in the WR and GK-Ex groups $(p<0.05)$ and higher in the GK-Ex group than in the WR group $(p<0.05)$. HDL (Fig. 3C) and LDL (Fig. 3D) cholesterol levels were higher in the GK group than in the WR group $(p<0.05)$ and higher in the GK group than in the GK-Ex group $(p<0.05)$.
Triglyceride (Fig. 3E) and insulin (Fig. 3F) levels were lower in the GK and GK-Ex groups than in the WR group $(p<0.05)$. There were no differences in adiponectin (Fig. 3G) and leptin (Fig. 3H) levels among the three groups.

\section{Muscle weight}

The soleus muscle weight was higher in the GK-Ex group than in the WR and GK groups (Fig. 4A). The soleus muscle weight per body weight was higher in the GK-Ex group than in the GK group (Fig. 4B). The plantaris muscle weight (Fig. 4C) and muscle weight per body weight (Fig. 4D) were higher in the GK-Ex group than in the WR and GK groups.

\section{Muscle histochemical properties}

The soleus muscles in the WR group contained three types of fibers: I, IIA, and IIC (Fig. 5A, B), whereas these muscles in the GK group contained only type I fibers (Fig. 5C, D). In the GK-Ex group, seven rats had only type I fibers (Fig. 5E, F), whereas the other three had fiber types: I, IIA, and IIC (Fig. 5G, H). The percentage of type I fibers was higher in the GK and GK-Ex groups than in the WR group ( $p<0.05$, Fig. 6A), whereas the percentage of type IIA fibers was lower in the GK-Ex group than in the WR group $(p<0.05)$. The CSA of type I fibers was larger in the GK-Ex group than in the WR and GK groups ( $p<0.05$, Fig. 6B), whereas the CSA of type IIA fibers was larger in the GK-Ex group than in the WR group $(p<0.05)$.

The plantaris muscles in all three groups contained three types of fibers: I, IIA, and IIB (Fig. 7). The percentages of type IIA and type IIB fibers were lower in the GK group than in the WR group $(p<0.05$, Fig. 6C), whereas these percentages were higher in the GK-Ex group than in the GK group $(p<0.05)$. There were no differences in the CSAs among the three groups, irrespective of fiber type (Fig. 6D).

\section{Muscle SDH activity and Pgc-1 $\alpha$ mRNA levels}

$\mathrm{SDH}$ activity in the soleus (Fig. 8A) and plantaris (Fig. 8B) muscles was lower in the GK group than in the WR group $(p<0.05)$ and higher in the GK-Ex group than in the GK group $(p<0.05)$.

Pgc- $1 \alpha$ mRNA levels in the soleus (Fig. 8C) and plantaris (Fig. 8D) muscles were lower in the GK group than in the WR group $(p<0.05)$ and higher in the GK-Ex group than in the GK group $(p<0.05)$. 
A
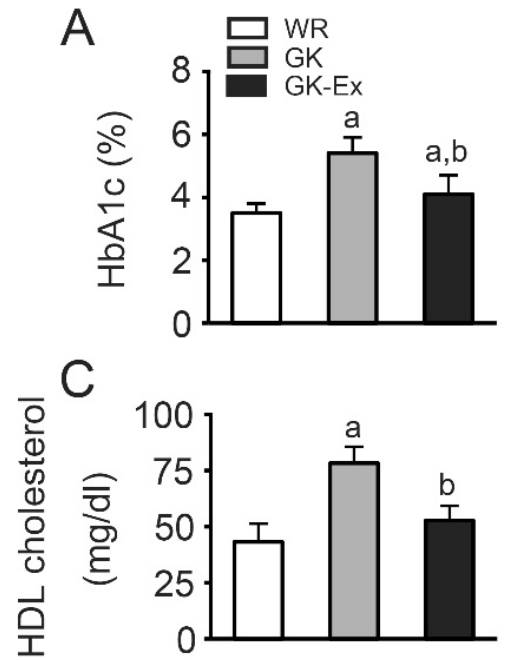

E
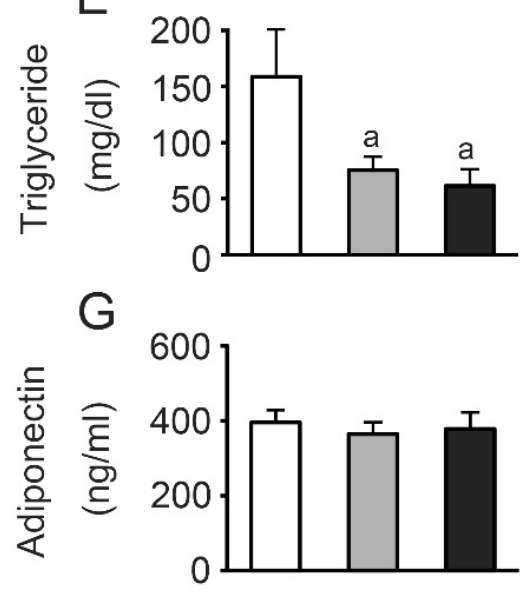

B
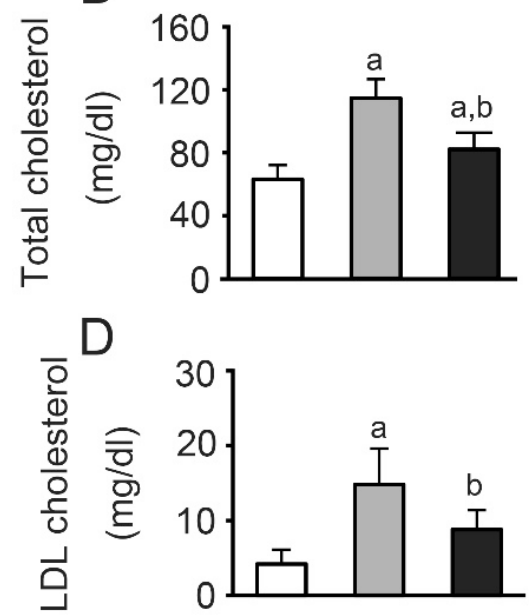

$\mathrm{F}$

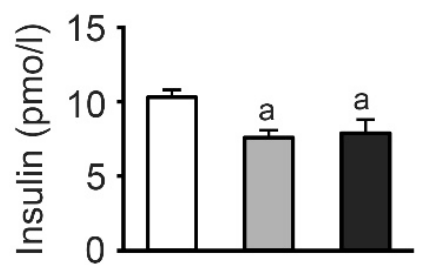

$\mathrm{H}$

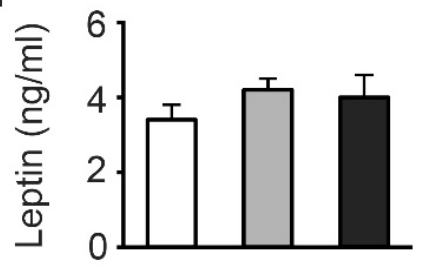

Fig. 3. HbA1c (A), total cholesterol (B), high density lipoprotein (HDL) cholesterol (C), low density lipoprotein (LDL) cholesterol (D), triglyceride (E), insulin (F), adiponectin (G), and leptin (H) levels in the Wistar (WR), Goto-Kakizaki (GK), and exercised Goto-Kakizaki (GK-Ex) groups. Values are expressed as mean $\pm \mathrm{SD}\left(\mathrm{n}=5\right.$ for WR and GK; $\mathrm{n}=10$ for GK-Ex). ${ }^{\mathbf{a}} p<0.05$ compared with WR; ${ }^{\mathbf{b}} p<0.05$ compared with GK.

A

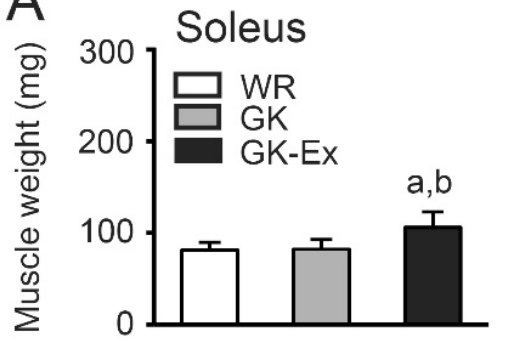

C

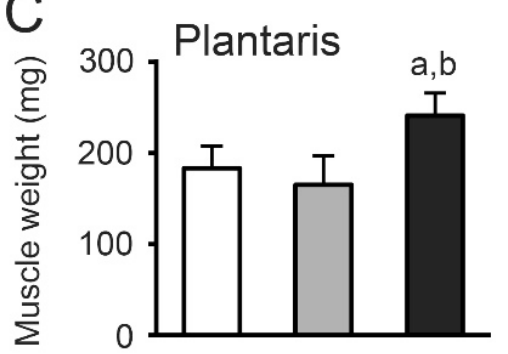

B
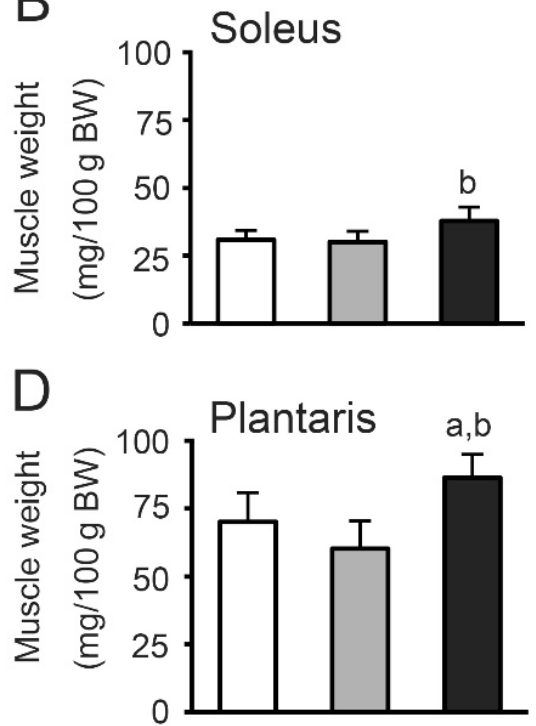

Fig. 4. Muscle weight (A, B) and relative weight per body weight $(\mathbf{C}, \mathbf{D})$ of the soleus and plantaris muscles in the Wistar (WR), GotoKakizaki (GK), and exercised Goto-Kakizaki (GK-Ex) groups. Values are expressed as mean \pm SD ( $n=5$ for WR and GK; $n=10$ for GK-Ex). a $p<0.05$ compared with WR; ${ }^{b} p<0.05$ compared with GK. 

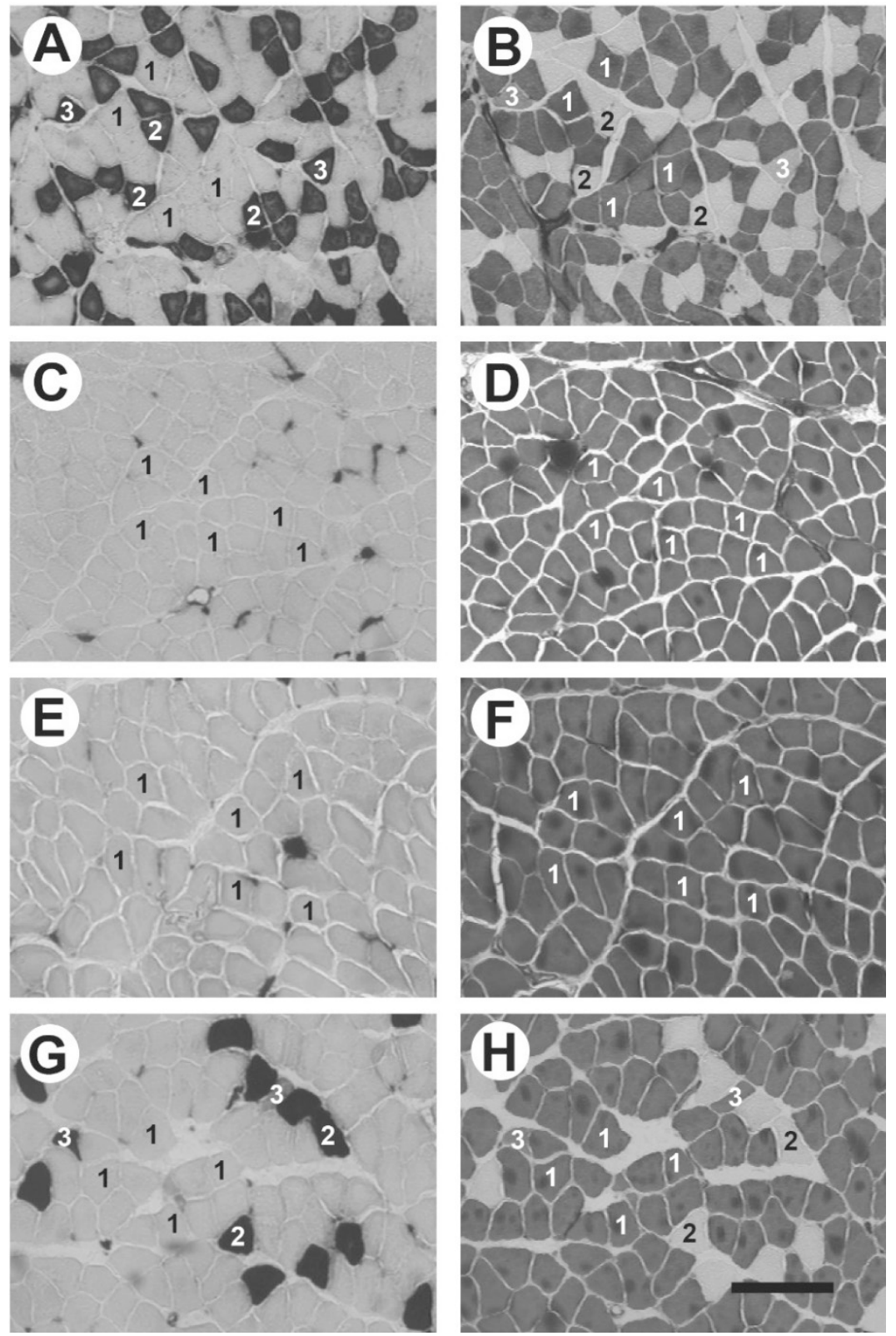

Fig. 5. Serial transverse sections of the soleus muscles of rats in the control (WR; A-B), Goto-Kakizaki (GK; C-D), and exercised Goto-Kakizaki (GK-Ex; E-H) groups stained for ATPase activity after preincubation at pH $10.4(\mathbf{A}, \mathbf{C}, \mathbf{E}$, and $\mathbf{G})$ and pH $4.5(\mathbf{B}, \mathbf{D}, \mathbf{F}$, and $\mathbf{H})$. In the GK-Ex group, the soleus muscles in seven rats contained only type I fibers $(\mathbf{E}, \mathbf{F})$, whereas these muscles in three rats contained three fiber types (G, H). 1, type I; 2, type IIA; 3, type IIC. Scale bar=200 $\mu \mathrm{m}$.
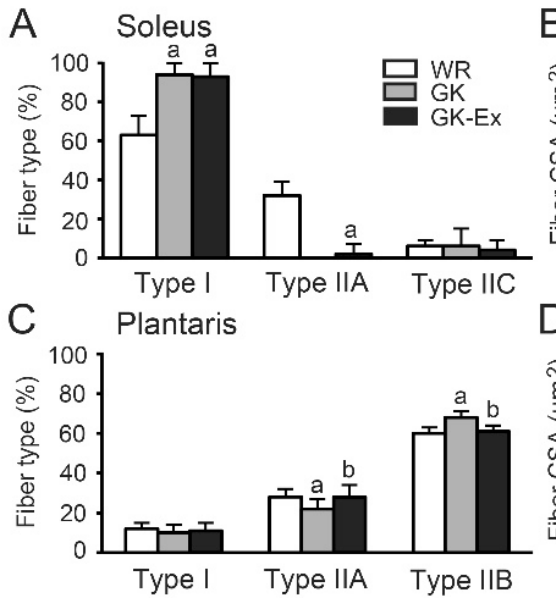

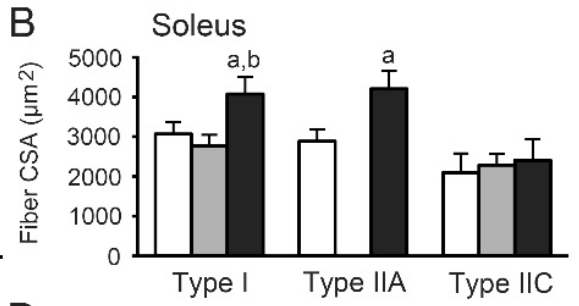

Plantaris

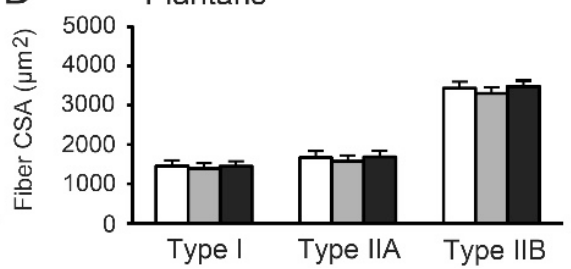

Fig. 6. Fiber type percentages (A, C) and cross-sectional areas (CSAs; B, D) in the soleus and plantaris muscles of the Wistar (WR), GotoKakizaki (GK), and exercised GotoKakizaki (GK-Ex) groups. Values are expressed as mean $\pm S D(n=5$ for WR and GK; $\mathrm{n}=10$ for GK-Ex). ${ }^{a} p<0.05$ compared with WR; ${ }^{b} p<0.05$ compared with GK. 
Relationship between voluntary running distance and the abovementioned parameters

In the GK-Ex group, there were negative relationships between voluntary running distance and HbA1c ( $r=-0.81, p<0.05$, Fig. 9A) and total cholesterol $(r=-0.83, p<0.05$, Fig. 9B) levels. There were positive relationships between voluntary running distance and both SDH activity ( $r=0.98, p<0.05$, Fig. 9C) and $P g c-1 \alpha$ mRNA levels $(r=0.70, p<0.05$, Fig. 9D) in the soleus muscle.
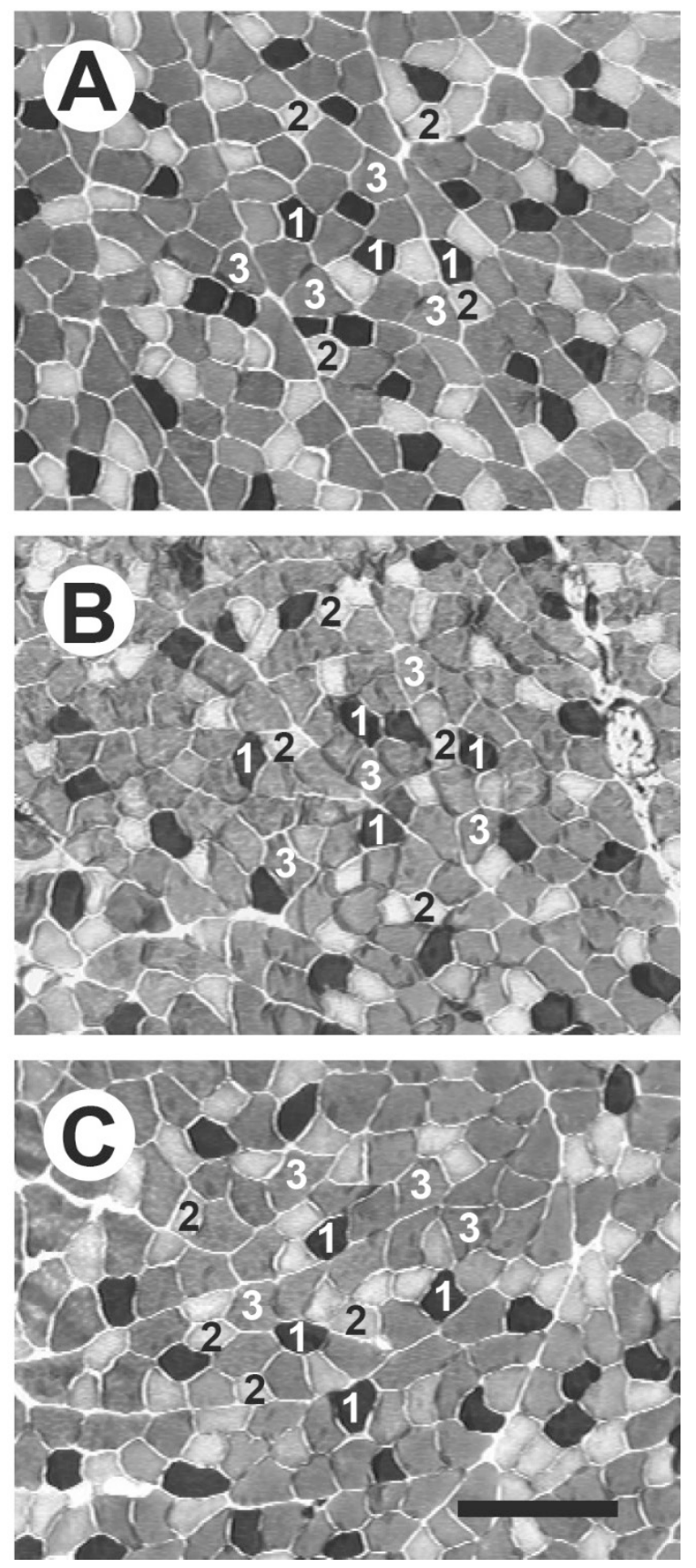

Fig. 7. Serial transverse sections of the plantaris muscles in rats of the Wistar (WR; A), Goto-Kakizaki (GK; B), and exercised Goto-Kakizaki (GK-Ex; C) groups stained for ATPase activity after preincubation at pH 4.5. 1, type I; 2, type IIA; 3, type IIB. Scale bar $=200 \mu \mathrm{m}$.

\section{Discussion}

\section{Voluntary running exercise and diabetes}

Some previous studies (Macia et al. 2018, Morifuji et al. 2012, Qi et al. 2011) observed that running training did not reduce the increased blood glucose levels in diabetic GK rats. In contrast, other studies (Fu et al. 2019, Kim et al. 2011) showed that the high blood glucose levels in diabetic GK rats were decreased by running training. However, all these aforementioned studies (Fu et al. 2019, Kim et al. 2011, Macia et al. 2018, Morifuji et al. 2012, Qi et al. 2011) used forced running training on a treadmill at a constant speed and time, and therefore, did not consider the effects of different running speeds and times. In this study, the growth-related increase in the fasting blood glucose levels of diabetic GK rats was inhibited by voluntary running exercise (Fig. 2C). Furthermore, a negative relationship between the amount of voluntary running distance and HbA1c was observed in diabetic GK rats (Fig. 9A), indicating that the onset and progression of type 2 diabetes were effectively inhibited when diabetic GK rats ran longer distances.

This study showed that nonobese diabetic GK rats have higher total and HDL cholesterol levels (Fig. 3B, C) and lower triglyceride levels than nondiabetic WR rats (Fig. 3E). Previous studies showed that metabolic syndrome (Takemura et al. 2017) and diabetic Otsuka Long-Evans Tokushima Fatty (OLETF) (Nagatomo et al. 2018) rats had higher total cholesterol, HDL cholesterol, and triglyceride levels. OLETF rats, which are obese and have hypertension, hyperlipidemia, hyperglycemia, hyperinsulinemia, and insulin resistance, were developed as obese diabetic models (Kawano et al. 1992). The increased levels of HDL cholesterol in metabolic syndrome and diabetic rats may be due to increased total cholesterol levels. The differences in triglyceride levels between diabetic OLETF and GK rats may be due to the respective presence and absence of obesity in the rats.

\section{Voluntary running exercise and muscle fiber type}

In diabetic GK rats, the slow soleus muscles contained only low-oxidative type I fibers, whereas in nondiabetic WR rats, these muscles contained three fiber types: low-oxidative type I and high-oxidative types IIA and IIC (Fig. 6A). Furthermore, the soleus muscles in diabetic GK rats had a higher percentage of low-oxidative type I fibers than those in nondiabetic Wistar rats. The 
fast plantaris muscles in diabetic GK rats had an increased percentage of low-oxidative type IIB fibers and a decreased percentage of high-oxidative type IIA fibers when compared to the corresponding percentages in WR and GK-Ex rats (Fig. 6C). These results correspond to those obtained in previous studies using nonobese GK (Gu et al. 2010, Nagatomo et al. 2011a, Yasuda et al. 2002, Yasuda et al. 2007) and obese OLETF (Nagatomo et al. 2018, Yasuda et al. 2001) rats.

Animals and humans with type 2 diabetes show a low percentage of high-oxidative fibers and a high percentage of low-oxidative fibers in skeletal muscles; a high percentage of low-oxidative fibers, especially type IIB fibers, was observed in the vastus lateralis muscles of patients with type 2 diabetes (Gaster et al. 2001, Märin et al. 1994, Nyholm et al. 1997, Oberbach et al. 2006). Obese Zucker rats with type 2 diabetes had a lower percentage of high-oxidative fibers in the soleus muscle than nonobese Zucker rats without type 2 diabetes, whereas obese Zucker rats without type 2 diabetes had a normal fiber type distribution (Adachi et al. 2007). The altered percentages in skeletal muscles are directly linked to blood glucose levels, but not to insulin levels or body weight, because the growth-related increase in blood glucose levels in rats with type 2 diabetes paralleled the increased percentage of low-oxidative type I fibers in the soleus muscle (Yasuda et al. 2002). Thus, the altered patterns of fiber types in the skeletal muscles of rats with type 2 diabetes are tightly linked to impaired glucose metabolism.

Voluntary running exercise inhibited the type shift from high-oxidative fibers to low-oxidative fibers in the plantaris muscle of diabetic GK rats (Fig. 6C). Inhibition of the fiber type shift induced by voluntary running exercise is thought to be due to enhanced oxidative metabolism in cells and tissues. However, we did not elucidate the reason why the diabetes-induced alteration in fiber type distribution was shifted to normal in the fast plantaris muscle, but not in the slow soleus muscle, by voluntary running exercise.
A

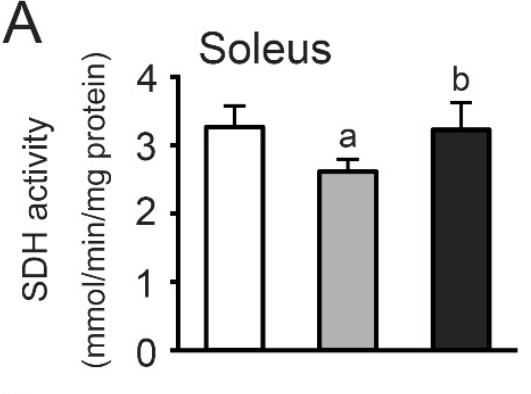

C

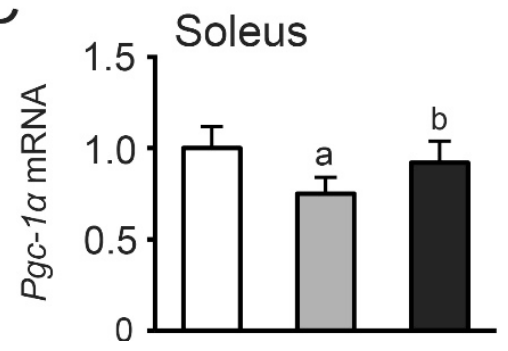

$\mathrm{B}$

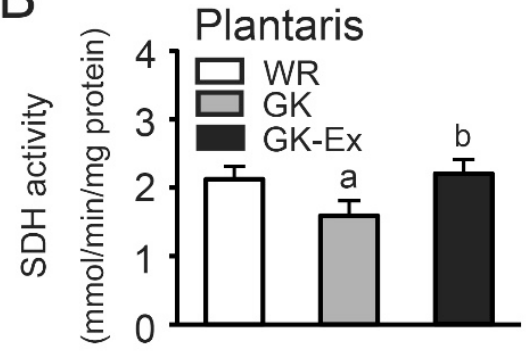

D

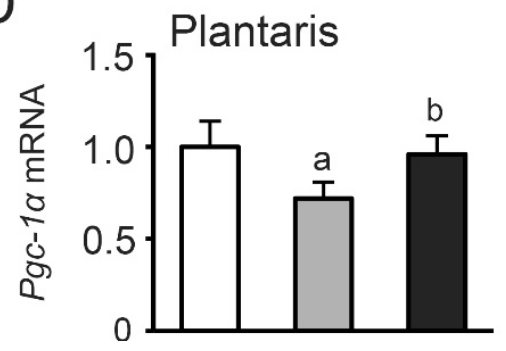

Fig. 8. Succinate dehydrogenase (SDH) activity (A, B) and peroxisome proliferator-activated receptor $\mathrm{Y}$ Coactivator-1a (Pgc-1a) mRNA levels (C, D) in the soleus and plantaris muscles of the Wistar (WR), Goto-Kakizaki (GK), and exercised Goto-Kakizaki (GK-Ex) groups. Values are expressed as mean $\pm S D(n=5$ for WR and GK; $\mathrm{n}=10$ for GK-EX). ${ }^{\mathrm{a}} p<0.05$ compared with WR; ${ }^{b} p<0.05$ compared with GK.

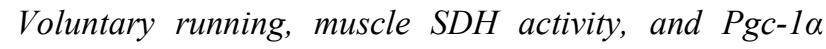
mRNA levels

Diabetic GK rats showed decreased muscle SDH activity (Fig. 8A, B) and Pgc-1 $\alpha$ mRNA levels (Fig. 8C, D) when compared with nondiabetic WR rats. PGC- $1 \alpha$ is a member of a family of transcription coactivators that plays central roles in the regulation of oxidative metabolism in cells and tissues (Liang and Ward 2006, Southgate et al. 2007). In skeletal muscles, PGC-1 $\alpha$ accelerates mitochondrial synthesis and promotes muscle fiber remodeling (Mortensen et al. 2006, Wu et al. 1999).
Transgenic mice with increased PGC- $1 \alpha$ expression in skeletal muscles showed an increased number of mitochondria and a fiber type shift, i.e. more oxidative and less glycolytic fibers (Miura et al. 2003, Miura et al. 2006). The decrease in oxidative activity is due to low Pgc-1 $\alpha$ mRNA levels, which may be induced by hyperglycemia. Diabetic GK rats exhibited hyperglycemia (Figs 2 and 3A), but not hypertriglyceridemia (Fig. 3E) or hyperinsulinemia (Fig. 3F). Obese diabetic OLETF rats also showed lower muscle oxidative capacity than nondiabetic Long-Evans Tokushima Otsuka (LETO) 
rats (Yasuda et al. 2001), but OLETF rats also exhibited hyperglycemia, hypertriglyceridemia, and hyperinsulinemia. Both diabetic GK and OLETF rats exhibit hyperglycemia. Therefore, the decreased oxidative capacity in the skeletal muscles of diabetic rats is thought to be due to hyperglycemia, but not hypertriglyceridemia or hyperinsulinemia. We concluded that the diabetesinduced decrease in SDH activity was inhibited by voluntary running exercise, which effectively maintained and improved oxidative metabolism in skeletal muscles.

Relationships between voluntary running distance and the abovementioned parameters

We observed that the running distances of individual rats were negatively related to $\mathrm{HbA1c}$ (Fig. 9A) and total cholesterol (Fig. 9B) levels and positively related to SDH activity (Fig. 9C) and $P g c-1 \alpha$ mRNA levels (Fig. 9D) in the soleus muscle, indicating that type 2 diabetes is effectively inhibited when diabetic GK rats ran longer distances. Voluntary running exercise, which is different from forced exercise, such as treadmill running, is effective as an exercise program because of the low stress.

A previous study (Yasuda et al. 2006) observed a negative relationship between voluntary running distance and the percentage of low-oxidative type I fibers in the soleus muscle of 10 OLETF rats. Furthermore, five OLETF rats with voluntary running distances $<7000 \mathrm{~m} /$ day had no high-oxidative type IIA fibers in the soleus muscle, whereas five OLETF rats with running distances $>7000 \mathrm{~m} /$ day showed a positive relationship between voluntary running distance and the percentage of type IIA fibers in the soleus muscle. In this study, seven diabetic GK rats had no high-oxidative type II fibers (Fig. 5E, F) after voluntary running exercise, whereas three had high-oxidative type IIA and type IIC fibers as well as low-oxidative type I fibers in the soleus muscle (Fig. 5G, H) after voluntary running exercise. However, there was no relationship between voluntary running distance and the fiber type percentages in the soleus and plantaris muscles in diabetic GK rats.
A
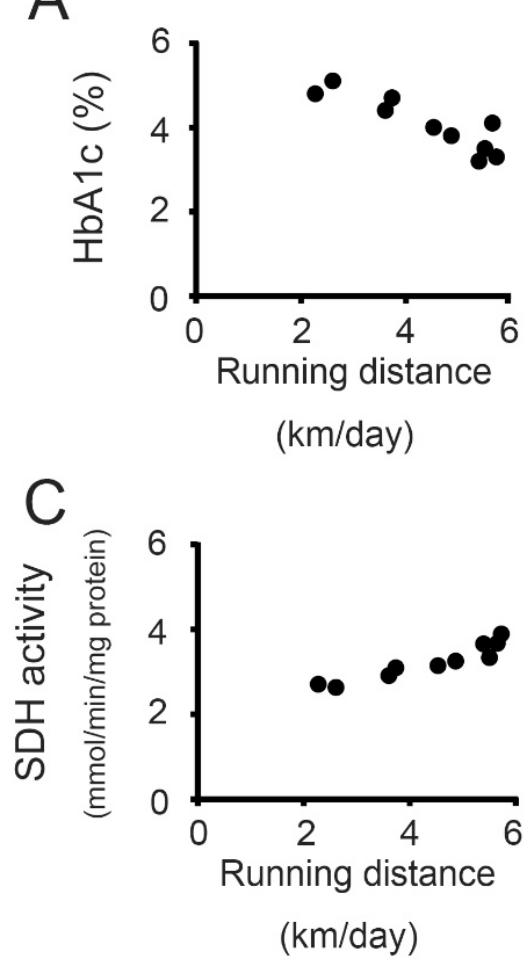

\section{Conclusions}

Growth-related increases in fasting blood glucose and HbAlc levels and decreases in the percentage of low-oxidative fibers and SDH activity in
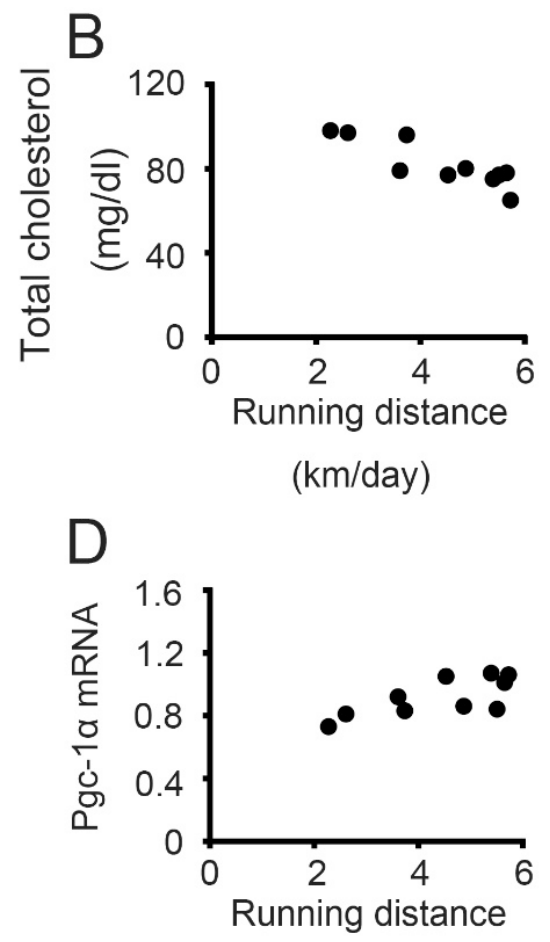

(km/day)
Fig. 9. Relationships between voluntary running distance and the HbA1c (A) and total cholesterol (B) levels, succinate dehydrogenase (SDH) activity (C), and peroxisome proliferator-activated receptor $\mathrm{y}$ coactivator-1a (PgC-1a) mRNA levels (D) in the soleus muscles of exercised Goto-Kakizaki rats $(n=10)$. Running distance was negatively related to both $\mathrm{HbA1C}(\mathrm{r}=-0.81, p<0.05)$ and total cholesterol $(r=-0.83, p<0.05)$ levels and positively related to both SDH activity $(r=0.98, p<0.05)$ and Pgc-1 $a$ mRNA levels $(r=0.70, p<0.05)$.

the skeletal muscles of diabetic rats were inhibited by voluntary running exercise. The observed inhibition of the decreased muscle oxidative capacity induced by voluntary running exercise was thought to be due to increased $P g c-1 \alpha$ mRNA levels, which are influenced by 
blood glucose levels.

HbAlc levels were negatively related to running distance, and SDH activity and $P g c-1 \alpha$ mRNA levels in the soleus muscle were positively related to running distance in the diabetic rats, indicating that the onset and progression of type 2 diabetes are effectively inhibited in nonobese diabetic rats that ran longer distances.

\section{Conflict of Interest}

There is no conflict of interest.

\section{Acknowledgements}

This study was supported by a Grant-in-Aid for Scientific Research from the Japan Society for the Promotion of Science.

\section{Authors Contributions}

Isuzu Nakamoto and Akihiko Ishihara conceived, designed, and performed the experiments, analyzed the data, and wrote the paper.

\section{References}

ADACHI T, KIKUCHI N, YASUHARA K, ANAHARA R, GU N, MATSUNAGA T, YAMAMURA T, MORI C, TSUJIMOTO G, TSUDA K, ISHIHARA A: Fibre type distribution and gene expression levels of both succinate dehydrogenase and peroxisome proliferator-activated receptor- $\gamma$ coactivator- $1 \alpha$ of fibres in the soleus muscle of Zucker diabetic fatty rats. Exp Physiol 92: 449-455, 2007. https://doi.org/10.1113/expphysiol.2006.035451

FU S, MENG Y, ZHANG W, WANG J, HE Y, HUANG L, CHEN H, KUANG J, DU H: Transcriptomic responses of skeletal muscle to acute exercise in diabetic Goto-Kakizaki rats. Front Physiol 10: 872, 2019. https://doi.org/10.3389/fphys.2019.00872

GASTER M, STAEHR P, BECK-NIELSEN H, SCHRØDER HD, HANDBERG A: GLUT4 is reduced in slow muscle fibers of type 2 diabetic patients: is insulin resistance in type 2 diabetes a slow, type 1 fiber disease? Diabetes 50: 1324-1329, 2001. https://doi.org/10.2337/diabetes.50.6.1324

GOTO Y, KAKIZAKI M, MASAKI N: Spontaneous diabetes produced by selective breeding of normal Wistar rats. Proc Jpn Acad 51: 80-85, 1975. https://doi.org/10.2183/pjab1945.51.80

GOTO Y, KAKIZAKI M, MASAKI N: Production of spontaneous diabetic rats by repetition of selective breeding. Tohoku J Exp 119: 85-90, 1976. https://doi.org/10.1620/tjem.119.85

GU N, NAGATOMO F, FUJINO H, TAKEDA I, TSUDA K, ISHIHARA A: Hyperbaric oxygen exposure improves blood glucose level and muscle oxidative capacity in rats with type 2 diabetes. Diabetes Technol Ther 12: 125-133, 2010. https://doi.org/10.1089/dia.2009.0104

ISHIHARA A, NAGATOMO F, FUJINO H, KONDO H, TSUDA K: Lifestyle-related disease and skeletal muscle: a review. J Phys Fitness Sports Med 1: 17-27, 2012. https://doi.org/10.7600/jpfsm.1.17

ISHIHARA A, ROY RR, OHIRA Y, IBATA Y, EDGERTON VR: Hypertrophy of rat plantaris muscle fibers after voluntary running with increasing loads. J Appl Physiol 84: 2183-2189, 1998. https://doi.org/10.1152/jappl.1998.84.6.2183

JENKINS DW, JENKS A: Exercise and diabetes: a narrative review. J Foot Ankle Surg 56: 968-974, 2017. https://doi.org/10.1053/j.jfas.2017.06.019

KAWANO K, HIRASHIMA T, MORI S, SAITOH Y, KUROSUMI M, NATORI T: Spontaneous long-term hyperglycemic rat with diabetic complications. Otsuka Long-Evans Tokushima Fatty (OLETF) strain. Diabetes 41: 1422-1428, 1992. https://doi.org/10.2337/diabetes.41.11.1422

KIM SS, KOO JH, KWON IS, OH YS, LEE SJ, KIM EJ, KIM WK, LEE J, CHO JY: Exercise training and selenium or a combined treatment ameliorates aberrant expression of glucose and lactate metabolic proteins in skeletal muscle in a rodent model of diabetes. Nutr Res Pract 5: 205-213, 2011. https://doi.org/10.4162/nrp.2011.5.3.205

LIANG H, WARD WF: PGC-1 $\alpha$ : a key regulator of energy metabolism. Adv Physiol Educ 30: 145-151, 2006. https://doi.org/10.1152/advan.00052.2006 
LIN J, WU H, TARR PT, ZHANG CY, WU Z, BOSS O, MICHAEL LF, PUIGSERVER P, ISOTANI E, OLSON EN, LOWELL BB, BASSEL-DUBY R, SPIEGELMAN BM: Transcriptional co-activator PGC-1 $\alpha$ drives the formation of slow-twitch muscle fibres. Nature 418: 797-801, 2002. https://doi.org/10.1038/nature00904

MACIA M, PECCHI E, DESROIS M, LAN C, VILMEN C, PORTHA B, BERNARD M, BENDAHAN D, GIANNESINI B: Exercise training impacts exercise tolerance and bioenergetics in gastrocnemius muscle of non-obese type-2 diabetic Goto-Kakizaki rat in vivo. Biochimie 148: 36-45, 2018. https://doi.org/10.1016/j.biochi.2018.02.014

MÅRIN P, ANDERSSON B, KROTKIEWSKI M, BJÖRNTORP P: Muscle fiber composition and capillary density in women and men with NIDDM. Diabetes Care 17: 382-386, 1994. https://doi.org/10.2337/diacare.17.5.382

MIURA S, KAI Y, ONO M, EZAKI O: Overexpression of peroxisome proliferator-activated receptor $\gamma$ coactivator-1 $\alpha$ (PGC-1 $\alpha$ ) down-regulates GLUT4 mRNA in skeletal muscles. J Biol Chem 278: 31385-31390, 2003. https://doi.org/10.1074/jbc.M304312200

MIURA S, TOMITSUKA E, KAMEI Y, YAMAZAKI T, KAI Y, TAMURA M, KITA K, NISHINO I, EZAKI O: Overexpression of peroxisome proliferators-activated receptor $\gamma$ co-activator- $1 \alpha$ leads to muscle atrophy with depletion of ATP. Am J Pathol 169: 1129-1139, 2006. https://doi.org/10.2353/ajpath.2006.060034

MORIFUJI T, MURAKAMI S, FUJITA N, KONDO H, FUJINO H: Exercise training prevents decrease in luminal capillary diameter of skeletal muscles in rats with type 2 diabetes. Sci World J 2012: 645891, 2012. https://doi.org/10.1100/2012/645891

MORTENSEN OH, FRANDSEN L, SCHJERLING P, NISHIMURA E, GRUNNET N: PGC-1 $\alpha$ and PGC-1 $\beta$ have both similar and distinct effects upon myofiber switching toward an oxidative phenotype. Am J Physiol Endocrinol Metab 291: E807-E816, 2006. https://doi.org/10.1152/ajpendo.00591.2005

NAGATOMO F, FUJINO H, KONDO H, GU N, TAKEDA I, ISHIOKA N, TSUDA K, ISHIHARA A: PGC-1 $\alpha$ mRNA level and oxidative capacity of the plantaris muscle in rats with metabolic syndrome, hypertension, and type 2 diabetes. Acta Histochem Cytochem 44: 73-80, 2011a. https://doi.org/10.1267/ahc.10041

NAGATOMO F, FUJINO H, KONDO H, KOUZAKI M, GU N, TAKEDA I, TSUDA K, ISHIHARA A: The effects of running exercise on oxidative capacity and PGC- $1 \alpha$ mRNA levels in the soleus muscle of rats with metabolic syndrome. J Physiol Sci 62: 105-114, 2012a. https://doi.org/10.1007/s12576-011-0188-1

NAGATOMO F, FUJINO H, KONDO H, SUZUKI H, KOUZAKI M, TAKEDA I, ISHIHARA A: PGC-1 $\alpha$ and FOXO1 mRNA levels and fiber characteristics of the soleus and plantaris muscles in rats after hindlimb unloading. Histol Histopathol 26: 1545-1553, 2011b. https://doi.org/10.14670/HH-26.1545

NAGATOMO F, FUJINO H, KONDO H, TAKEDA I, TSUDA K, ISHIHARA A: High-fat diet-induced reduction of peroxisome proliferator-activated receptor- $\gamma$ coactivotor- $1 \alpha$ mRNA levels and oxidative capacity in the soleus muscle of rats with metabolic syndrome. Nutr Res 32: 144-151, $2012 \mathrm{~b}$. https://doi.org/10.1016/j.nutres.2011.12.015

NAGATOMO F, GU N, FUJINO H, TAKEDA I, TSUDA K, ISHIHARA A: Skeletal muscle characteristics of rats with obesity, diabetes, hypertension, and hyperlipidemia. J Atheroscler Thromb 16: 576-585, 2009. https://doi.org/10.5551/jat.1065

NAGATOMO F, TAKEMURA A, ROY RR, FUJINO H, KONDO H, ISHIHARA A: Mild hyperbaric oxygen inhibits the growth-related decline in skeletal muscle oxidative capacity and prevents hyperglycemia in rats with type 2 diabetes mellitus. J Diabetes 10: 753-763, 2018. https://doi.org/10.1111/1753-0407.12666

NYHOLM B, QU Z, KAAL A, PEDERSEN SB, GRAVHOLT CH, ANDERSEN JL, SALTIN B, SCHMITZ O: Evidence of an increased number of type IIb muscle fibers in insulin-resistant first-degree relatives of patients with NIDDM. Diabetes 46: 1822-1828, 1997. https://doi.org/10.2337/diabetes.46.11.1822

OBERBACH A, BOSSENZ Y, LEHMANN S, NIEBAUER J, ADAMS V, PASCHKE R, SCHÖN MR, BLÜHER M, PUNKT K: Altered fiber distribution and fiber-specific glycolytic and oxidative enzyme activity in skeletal muscle of patients with type 2 diabetes. Diabetes Care 29: 895-900, 2006. https://doi.org/10.2337/diacare.29.04.06.dc05-1854

PHIELIX E, MENSIN M: Type 2 diabetes mellitus and skeletal muscle metabolic function. Physiol Behav 94: 252-258, 2008. https://doi.org/10.1016/j.physbeh.2008.01.020 
PUIGSERVER P: Tissue-specific regulation of metabolic pathways through the transcriptional coactivator PGC-1 $\alpha$. Int J Obes 29 (Suppl 1): S5-S9, 2005. https://doi.org/10.1038/sj.ijo.0802905

QI Z, HE J, ZHANG Y, SHAO Y, DING S: Exercise training attenuates oxidative stress and decreases p53 protein content in skeletal muscle of type 2 diabetic Goto-Kakizaki rats. Free Rad Biol Med 50: 794-800, 2011. https://doi.org/10.1016/j.freeradbiomed.2010.12.022

SCHULER M, ALI F, CHAMBON C, DUTEIL D, BORNERT JM, TARDIVEL A, DESVERGNE B, WAHLI W, CHAMBON P, METZGER D: PGC1 $\alpha$ expression is controlled in skeletal muscles by PPARß, whose ablation results in fiber-type switching, obesity, and type 2 diabetes. Cell Metab 4: 407-414, 2006. https://doi.org/10.1016/j.cmet.2006.10.003

SOUTHGATE RJ, NEILL B, PRELOVSEK O, EL-OSTA A, KAMEI Y, MIURA S, EZAKI O, MCLOUGHLIN TJ, ZHANG W, UNTERMAN TG, FEBBRAIO MA: FOXO1 regulates the expression of 4E-BP1 and inhibits mTOR signaling in mammalian skeletal muscle. J Biol Chem 282: 21176-21186, 2007. https://doi.org/10.1074/jbc.M702039200

TAKEMURA A, ISHIHARA A: Mild hyperbaric oxygen inhibits growth-related decrease in muscle oxidative capacity of rats with metabolic syndrome. J Atheroscler Thromb 24: 26-38, 2017. https://doi.org/10.5551/jat.34686

WENDE AR, HUSS JM, SCHAEFFER PJ, GIGUÈRE V, KELLY DP: PGC-1 $\alpha$ coactivates PDK4 gene expression via the orphan nuclear receptor ERR $\alpha$ : a mechanism for transcriptional control of muscle glucose metabolism. Mol Cell Biol 25: 10684-10694, 2005. https://doi.org/10.1128/MCB.25.24.10684-10694.2005

WU H, KANATOUS SB, THURMOND FA, GALLARDO T, ISOTANI E, BASSEL-DUBY R, WILLIAMS RS: Regulation of mitochondrial biogenesis in skeletal muscle by CaMK. Science 296: 349-352, 2002. https://doi.org/10.1126/science.1071163

WU Z, PUIGSERFVER P, ANDERSSON U, ZHANG C, ADELMANT G, MOOTHA V, TROY A, CINTI S, LOWELL B, SCARPULLA RC, SPIEGELMAN BM: Mechanisms controlling mitochondrial biogenesis and respiration through the thermogenic coactivator PGC-1. Cell 98: 115-124, 1999. https://doi.org/10.1016/S0092-8674(00)80611-X

YASUDA K, ADACHI T, GU N, MATSUMOTO A, MATSUNAGA T, TSUJIMOTO G, TSUDA K, ISHIHARA A: Effects of hyperbaric exposure with high oxygen concentration on glucose and insulin levels and skeletal muscle-fiber properties in diabetic rats. Muscle Nerve 35: 337-343, 2007. https://doi.org/10.1002/mus.20692

YASUDA K, ADACHI T, KIKUCHI N, TSUJIMOTO G, AOKI N, TSUDA K, ISHIHARA A: Effects of running exercise on fibre-type distribution of soleus and plantaris muscles in diabetic Otsuka Long-Evans Tokushima fatty rats. Diabetes Obes Metab 8: 311-321, 2006. https://doi.org/10.1111/j.1463-1326.2005.00507.x

YASUDA K, ISHIHARA A, ADACHI T, SHIHARA N, SEINO Y, TSUDA K: Growth-related changes in skeletal muscle fiber type and insulin resistance in diabetic Otsuka Long-Evans Tokushima Fatty rats. Acta Histochem Cytochem 34: 371-382, 2001. https://doi.org/10.1267/ahc.34.371

YASUDA K, NISHIKAWA W, IWANAKA N, NAKAMURA E, SEINO Y, TSUDA K, ISHIHARA A: Abnormality in fibre type distribution of soleus and plantaris muscles in non-obese diabetic Goto-Kakizaki rats. Clin Exp Pharmacol Physiol 29: 1001-1008, 2002. https://doi.org/10.1046/j.1440-1681.2002.03757.x 